\title{
An investigation of the association between religious coping, fatigue, anxiety and depressive symptoms during the COVID-19 pandemic in Morocco: a web- based cross-sectional survey
}

Btissame Zarrouq ${ }^{1,2^{*}}$, Nivine Abbas ${ }^{3}$, Jaouad El Hilaly ${ }^{4}$, Achraf El Asri ${ }^{1}$, Samira Abbouyi ${ }^{1,2}$, Majid Omari ${ }^{1,5}$, Hicham Malki ${ }^{1}$, Samira Bouazza ${ }^{1,2}$, Salma Ghofrane Moutawakkil ${ }^{1,2}$, Karima Halim ${ }^{5,6}$ and

Mohammed Elamine Ragala ${ }^{2,5}$

\begin{abstract}
Background: The Coronavirus Disease 2019 (COVID-19) pandemic has triggered fear and distress among the public, thus potentiating the incidence rate of anxiety and depression. This study aims to investigate the psychological effect of quarantine on persons living in Morocco when the first COVID-19 cases were identified. The associations between anxiety, depression symptoms, and their predictors (sociodemographics, fatigue, and religious coping) were examined.

Methods: A web-based cross-sectional survey, with a total of 1435 participants ( $\geq 18$ years) recruited anonymously, was conducted during the COVID-19 pandemic (from 3 to 30 April 2020). A structured questionnaire was used to assess psychosocial factors, COVID-19 epidemic-related factors, and religious coping. Religious coping, fatigue, and depression, and anxiety were measured by Brief Religious Coping Scale (Brief RCOPE), Chalder Fatigue Scale (CFS), and Hospital Anxiety and Depression Scale (HADS), respectively. A generalized linear model (logistic regression) was used to determine the predictive factors of depression and anxiety.
\end{abstract}

Results: The prevalence of anxiety and depression was $43.0 \%(n=621)$ and 53.0\% $(n=766)$, respectively. Both were associated with female gender, household income decline, tracking COVID-19 news, and fear to contract COVID-19 (aOR $=1.36$ to 2.85$)$. Additionally, 32.0\% $(n=453)$ and $26.0 \%(n=372)$ reported severe physical fatigue, and mental fatigue, respectively. Both latter factors were significantly and positively associated with depression as well as with anxiety. Depressive and anxious patients used more negative religious coping, while positive religious coping was slightly associated with depression.

\footnotetext{
*Correspondence: btissame.zarrouq@usmba.ac.ma

'Laboratory of Epidemiology and Research in Health Sciences, Faculty of

Medicine and Pharmacy, Sidi Mohamed Ben Abdellah University, Fez,

Morocco

${ }^{2}$ Teachers Training College (Ecole Normale Superieure), Department of Biology and Geology, Sidi Mohamed Ben Abdellah University, Fez, Morocco Full list of author information is available at the end of the article
}

(C) The Author(s). 2021 Open Access This article is licensed under a Creative Commons Attribution 4.0 International License, which permits use, sharing, adaptation, distribution and reproduction in any medium or format, as long as you give appropriate credit to the original author(s) and the source, provide a link to the Creative Commons licence, and indicate if changes were made. The images or other third party material in this article are included in the article's Creative Commons licence, unless indicated otherwise in a credit line to the material. If material is not included in the article's Creative Commons licence and your intended use is not permitted by statutory regulation or exceeds the permitted use, you will need to obtain permission directly from the copyright holder. To view a copy of this licence, visit http://creativecommons.org/licenses/by/4.0/ The Creative Commons Public Domain Dedication waiver (http://creativecommons.org/publicdomain/zero/1.0/) applies to the data made available in this article, unless otherwise stated in a credit line to the data. 
Conclusion: In this online survey of the general population in Morocco, anxiety and depressive symptoms are prevalent during the COVID-19 pandemic. Pandemic and psychosocial factors, such as female gender, income decline, infection fears, massive COVID-19 news exposure, negative religious coping, and fatigue were associated with increased risk of depression and anxiety symptoms. Psychosocial and financial support should be provided to the quarantined population.

Keywords: Depression, Anxiety, Fatigue, Religious coping, COVID-19, Quarantine, Morocco

\section{Background}

Coronavirus disease 2019 (COVID-19) was first reported in China. Shortly thereafter, the disease spread all over the world to became a global pandemic [1,2]. Since the severe acute respiratory syndrome outbreak in 2003, COVID - 19 is deemed to be highly contagious; it has affected 219 countries in record time [3]. On March 2nd, 2020, the first coronavirus case was officially confirmed in Morocco [4]. Up to April 10th 2021, 500,948 have been diagnosed as COVID-19 positive, of which 8885 were fatal [5]. Moroccan authorities, for the sake of control and prevention, have implemented urgently a package of restrictive measures, such as isolation of suspected and diagnosed cases, cancelling parties, extending holidays, closing schools, and complying with stay-athome orders [6].

A couple of studies have reported that the outbreaks of fatal infectious diseases impact negatively people's mental health and well-being [7]. Indeed, concerns about the mental health and psychological adjustment of the public have been arising due to the COVID-19's quick outbreaks and high mortality. Accordingly, a couple of works have reported significant psychosocial impacts of the COVID-19 quarantine on mental and physical health, such as post-traumatic stress symptoms, depression, anxiety, fear, and confusion among general population and medical workers as well. The severity of psychological disorders varies depending on sociodemographic factors, such as age, gender, area of living, social media, income, social support, religiosity, having relatives infected or died from COVID-19 $[8,9]$, guilt about the effects of contagion [10], inadequate or fake information especially from unauthorized sources or media [11, 12], uncertainty and unpredictability around COVID-19 [13], quarantine duration, frustration, fear of losing friends and family [11], loneliness, boredom, inadequate supplies and health equipment, financial loss, and stigma $[10,14]$. All these stressors increase anxiety and depression in the quarantined population. Moreover, studies showed that prolonged feelings of distress and worry can increase levels of fatigue [15].

On the other hand, people experiencing adverse life events tend to take religion as a source of comfort [16], and adopt more religious coping [17-20]. Religious coping can be defined as the way individuals use cognitive or behavioral strategies based on religious beliefs or practices to cope with stress and life problems [21]. This can include reading holy scriptures, seeking counsel from religious leaders, and reducing unpleasant thoughts using religious means [19]. Literature has argued that religiosity can be seen as a framework of meaning-making that is associated with decreased psychological distress and thus a powerful resource for mental health $[22,23]$. Positive religious coping provides a source of social support [24]. The majority of the Moroccan population is Muslim. Islamic beliefs state that every event, whether positive or negative, has a purpose, and spiritual growth requires enormous patience and commitment [17, 25]. Literature has mentioned that the Islamic religion plays an important role in protecting people from difficult mental health outcomes including attempts to suicide [19].

Although quarantine measures are successful in reducing or terminating the COVID-19 outbreak in different areas of the world, the adverse effects of quarantine have not previously been studied systematically. Literature has stated that there is not enough data available about the effect of the COVID - 19 pandemic on mental health problems among the general population $[10,26]$.

Up to our knowledge, information about the prevalence of depression, anxiety, and fatigue of Moroccan citizens, and their association with religious coping during the COVID-19 outbreak have not been studied yet. To this end, we conducted an online investigation during the first wave of COVID-19 pandemic to investigate the psychological effect of quarantine on people's psychological symptoms, mainly depression, anxiety, and their associations with the sociodemographic, fatigue and religious coping factors.

\section{Methods \\ Participants}

In this study, the snowball method was adopted to carry out the distribution of questionnaires due to the difficulty of reaching people during the COVID-19 total lockdown. Ten initial seeds were chosen to ensure a broad representation of age, gender, and educational level. These seeds sent the questionnaire link, via WhatsApp groups, Facebook groups, and other social media, to other participants who must be Moroccan citizens, 
aged more than 18 years, and so it goes on. The participants were directed to the survey link through Google form and responded only once to the questionnaire voluntarily and anonymously. The snowball sampling process continued between 3 to 30 April 2020 until sufficient sample size was reached. The online snowball sampling does not allow an assessment of the response rate. Apart from the seed vertices, the researchers do not have control over which vertices are included in the sample.

All respondents had provided electronic informed consent before starting the investigation. Ethical approval was obtained from the hospital-university ethics committee of Sidi Mohamed Ben Abdellah University ( $\mathrm{N}^{\circ} 09 /$ 20). Researchers had ensured that the internationally recognized ethical principles for research involving human subjects were respected throughout this research, and all methods were carried out per relevant guidelines and regulations.

\section{Measures}

This online survey was implemented by using a structured questionnaire composed of 56 multiple-choice questions (Supplementary file). It took approximately 15 min to be completed.

\section{Sociodemographics}

Sociodemographic data including participants' age, gender, education, marital status, parental status, employment status, and living arrangements were monitored. Participants were classified according to their level of education (higher, secondary, and primary education), age stages, employment status (private sector, public sector, self-employment), and living arrangement (living alone or with others).

\section{COVID-19-related information sources, knowledge and worry about COVID-19}

The frequency with which the respondents received COVID-19-related information was explored, the COVID-19 Knowledge (route of transmission, the availability of medicines, the number of infected cases and death, advice on prevention of the COVID-19) was also reported. Besides, the levels of adherence to quarantine and infection control directives (always washing hands, wearing a mask, and covering mouth when coughing and sneezing) were investigated. The participants were asked to report their concern about COVID-19 (COVID-19 infection of relatives and acquaintances, fear of death from this disease, chronic disease, and income decline).

\section{Anxiety, depression, fatigue, and religiosity}

The psychological impact of COVID-19 and quarantine was evaluated by the Hospital Anxiety and Depression Scale (HADS) [27]. It includes 14 items assessing anxiety (7 items) and depression (7 items), which are rated on a 4-point Likert type (from 0 to 3 ). The scores in each subscale are computed by summing the corresponding items, with maximum scores of 21 for each subscale. Zigmond and Snaith have advocated cut-offs between 8 and 10 for possible cases, and scores of 11 or more for definite cases of depression and anxiety [27]. Choosing the more conventional cut-off point of 11 would have missed out a significant proportion of people with anxiety and depressive symptoms. In this study, the cut-off of 8 was chosen for the Arabic version of HADS scales. Participants who obtained a score $>7$ on HADSDepression subscale (HADS-D) and /or HADS-Anxiety subscale (HADS-A) were considered as having symptoms suggestive of depression and/ or anxiety, respectively [28]. The HADS scale was chosen because it is easy and brief, and measures both anxiety and depressive symptoms with good reliability and validity in general population [28]. However, other scales, such as the Center for Epidemiologic Studies Depression Scale (CESD), and the Patient Health Questionnaire-9 (PHQ-9) measure only depressive symptoms. The former one is too long, while the latter one has a sensitive and unsuitable item for a general population during the stressful time of a pandemic [29]. The reliability and validity of the Arabic version of the HADS scale were previously reported [30]. The internal consistency of the HADS scales in the current study is acceptable; and this is true for both anxiety $(\alpha-$ Cronbach $=0.88)$ and depression $(\alpha-$ Cronbach $=0.76$ ).

Physical and mental fatigue was assessed by the Chalder Fatigue Scale (CFS) [31], and a validated Arabic version was used [32]. It consists of 11 items and two dimensions: physical fatigue (7 items) and mental fatigue (4 items). Participants were asked to mention their experienced symptoms of mental and physical fatigue in the last 2 weeks. In the current work, the internal consistency of the scale is significant; the Cronbach's alpha of CFS-physical fatigue was acceptable ( $\alpha$-Cronbach $=0.82$ ), whereas that of CFS-mental fatigue was questionable $(\alpha$-Cronbach $=0.61)$.

Religious coping was evaluated with the Brief Religious Coping Scale (Brief RCOPE). This scale is a 14-item measure of religious coping with crisis, trauma, and transition [33]. Brief RCOPE is the most commonly used measure of religious coping in the literature [34]. This scale is divided into two subscales: positive and negative religious coping. The positive religious coping subscale (P RECOPE) of the Brief RCOPE taps into a sense of connectedness with a transcendent force, a secure 
relationship with a caring God, and a belief that life has a greater benevolent meaning. The negative religious coping subscale (N RECOPE) of the Brief RCOPE is characterized by signs of spiritual tension, conflict and struggle with God and others, spiritual questioning and doubting, and interpersonal religious discontent [33]. Both Brief RCOPE subscales range from 7 (low) to 28 (high). A four-point Likert scale was used with this scale, and the response options were from 1 (strongly disagree) to 4 (strongly agree) [17]. The reliability and validity of the Arabic version of Brief RCOPE were established in a previous study [17]. P RECOPE and N RECOPE had high internal consistency in this study (Cronbach's $\alpha==$ $0.85,0.80$, respectively).

\section{Statistical analyses}

The sample size was calculated based on the estimated rate of depressive symptoms in the general population. Epidemiological data reported the lifetime prevalence of depressive symptoms in the Moroccan population as $26.5 \%$ [35], and the prevalence of anxiety as $25.5 \%$ [36]. Considering the likelihood of increased rates of depressive and anxiety symptoms during pandemics, we hypothesized a rate of $36.5 \%$ for depressive and anxiety symptoms in the general population. With a significance level set at .05 , and an absolute error of $0.1 \%$, we estimated a minimum sample size of 1435 for the current study.

All statistics were done using $\mathrm{R}$ software v.4.0.4 (http://www.r-project.org) implemented with gtsummary, Raven, Psych, EpiR, and tidyverse packages. Before conducting the study, a pilot test was conducted on 40 participants to assess the right connotation of each question. The results of the pilot study were not included in the analysis. The internal consistency was assessed using split-half reliability by splitting the test in half based on odd-numbered and even-numbered questions; each half of the test was administered to the same individuals $(N=150)$. The correlation between the scores for both halves was determined. Besides, the factorial structure of the 3 scales (HADS, CFS, RCOPE) were examined on this first sample $(N=150)$ using Exploratory Factor Analysis (EFA) (data not shown).

Descriptive statistics were used to examine the characteristics of the study population. Categorical variables were depicted in percentages and frequencies. Continuous variables were presented in means and standard deviation. The number of subjects with depression (HADS-depression subscale scores $\geq 8$ ) and anxiety (HADS anxiety subscale scores $\geq 8$ ) was computed. Chisquared statistics were used to evaluate the associations between sociodemographic characteristics, depression, and anxiety. The assumptions for the general linear model were tested; and since they were not fulfilled, univariate and multivariate logistic regression, as a generalized linear model (GLM), were performed to generate the outcome of the dependent variables (depression and anxiety) from an exponential family of distribution. It was used to reveal the variables that are independently associated with depressive and anxious symptoms, test our previous hypothesis that COVID-19 related independent variables would account for a significant amount of depression and anxiety variance. Pseudo Rsquared values were calculated using the Nagelkerke's method [37]. The associations were presented using odds ratios (ORs) and their 95\% confidence. The level of significance was set as $p<0.05$ (two-tailed).

\section{Results}

Out of 1530 questionnaires collected, 1435 (93.7\%) questionnaires were fully completed by Moroccan citizens aged more than 18 years. The usage of an online snowball sampling does not permit assessing the survey response rate, as there is no way to determine exactly how many people received the link and did not respond to it.

Participant's average age was $32.2 \pm 10.5$ years (age ranged from 18 and 74 years). More than half of the participants were male $(n=811,57.0 \%)$, not married $(n=$ $827,58.0 \%)$, and employed in the public sector $(n=769$, $54.0 \%)$. Most respondents were well-educated $(n=1332$, 93.0\%), and had no chronic disease $(n=1312,91.0 \%)$ (Table 1).

Regarding knowledge about COVID-19, nearly all respondents $(n=1301,91.0 \%)$ showed a need to be regularly updated with the latest information about COVID 19 (route of transmission, the availability of medicines, the number of infected cases and death, and advice on COVID-19 control and prevention). Most participants expressed a high level of compliance with quarantine and protective measures $(n=$ 1213, 85.0\%; and $n=979,68.0 \%$ respectively), whereas $32.0 \%(n=454)$ of participants expressed a high level of fear to contract COVID-19.

Among the 1435 participants, $53.0 \%(n=766)$ subjects were found to be depressed, $43.0 \%(n=621)$ were anxious, $32.0 \%(n=453)$ were suffering from severe physical fatigue, and $26.0 \%(n=372)$ were suffering from mental fatigue. Concerning religious coping, the participants' mean score of P RCOPE was high $(\mathrm{M}=17.8, \mathrm{SD}=4.5)$, while the mean score of $\mathrm{N}$ RCOPE was low $(\mathrm{M}=9.3$, $\mathrm{SD}=3.2$ ) (both Brief RCOPE subscales range from 7 (low) to 28 (high)).

The association between depression, anxiety and sociodemographic independent variables was assessed by the Chi-square test. As shown in Table 2, the younger age ( $\leq 45$ years) (depression $\mathrm{OR}=1.81, p<0.001$; anxiety $\mathrm{OR}=1.67, p<0.001$ ), female gender (depression $\mathrm{OR}=$ 1.63, $p<0.001$; anxiety $\mathrm{OR}=2.28, p<0.001$ ), household 
Table 1 Descriptive statistics of socio-demographic and psychological variables

\begin{tabular}{|c|c|c|}
\hline \multirow[t]{2}{*}{ Variable } & \multicolumn{2}{|l|}{$N=1435$} \\
\hline & $n(\%)$ & Mean (SD) \\
\hline Age (Years) & & $32.2(10.5)$ \\
\hline \multicolumn{3}{|l|}{ Age stages (Years) } \\
\hline$\leq 45$ & $1234(86.0)$ & \\
\hline$>45$ & $201(14.0)$ & \\
\hline \multicolumn{3}{|l|}{ Gender } \\
\hline Female & $624(43.0)$ & \\
\hline Male & $811(57.0)$ & \\
\hline \multicolumn{3}{|l|}{ Marital status } \\
\hline Married & $608(42.0)$ & \\
\hline Not married & $827(58.0)$ & \\
\hline \multicolumn{3}{|l|}{ Status as a parent } \\
\hline Having children & $469(33.0)$ & \\
\hline No children & $966(67.0)$ & \\
\hline \multicolumn{3}{|l|}{ Education } \\
\hline Higher education & $1332(93.0)$ & \\
\hline Primary or secondary education & $103(7.0)$ & \\
\hline \multicolumn{3}{|l|}{ Living arrangements } \\
\hline Alone & $122(8.5)$ & \\
\hline Not alone & $1313(91.5)$ & \\
\hline \multicolumn{3}{|l|}{ Employment status } \\
\hline Employed in the private sector & $108(7.1)$ & \\
\hline Employed in the public sector & $769(54.0)$ & \\
\hline Retired & $30(2.1)$ & \\
\hline Self-employed & $75(5.2)$ & \\
\hline Student & $373(26.0)$ & \\
\hline Unemployed & $80(5.6)$ & \\
\hline \multicolumn{3}{|l|}{ Household income decline } \\
\hline Yes & $403(28.0)$ & \\
\hline No & $1032(72.0)$ & \\
\hline \multicolumn{3}{|c|}{ Life satisfaction during the COVID-19 pandemic } \\
\hline Satisfied & $1124(78.0)$ & \\
\hline Not satisfied & $311(22.0)$ & \\
\hline \multicolumn{3}{|l|}{ Looked up regular news } \\
\hline Regularly & $1301(91.0)$ & \\
\hline Seldom & $134(9.0)$ & \\
\hline \multicolumn{3}{|l|}{ Compliance with protective measures } \\
\hline High & $979(68.0)$ & \\
\hline Low & $456(32.0)$ & \\
\hline \multicolumn{3}{|l|}{ Compliance with quarantine measures } \\
\hline High & $1213(85.0)$ & \\
\hline Low & $222(15.0)$ & \\
\hline \multicolumn{3}{|l|}{ Chronic illness } \\
\hline Yes & $123(9.0)$ & \\
\hline
\end{tabular}


Table 1 Descriptive statistics of socio-demographic and psychological variables (Continued)

\begin{tabular}{|c|c|c|}
\hline \multirow[t]{2}{*}{ Variable } & \multicolumn{2}{|l|}{$N=1435$} \\
\hline & $n(\%)$ & Mean (SD) \\
\hline No & $1312(91.0)$ & \\
\hline \multicolumn{3}{|l|}{ Fear of COVID-19 } \\
\hline High & $454(32.0)$ & \\
\hline Low & $981(68.0)$ & \\
\hline \multicolumn{3}{|l|}{ Fear of dying from COVID-19 } \\
\hline High & $100(7.0)$ & \\
\hline Low & $1335(93.0)$ & \\
\hline \multicolumn{3}{|c|}{ Know someone died from COVID-19 } \\
\hline Yes & $34(2.0)$ & \\
\hline No & $1401(98.0)$ & \\
\hline \multicolumn{3}{|l|}{ Depression } \\
\hline Positive & $766(53.0)$ & $10.2(2.8)$ \\
\hline Negative & $669(47.0)$ & $3.6(1.8)$ \\
\hline \multicolumn{3}{|l|}{ Anxiety } \\
\hline Positive & $621(43.0)$ & $10.6(3.4)$ \\
\hline Negative & $814(57.0)$ & $3.1(1.9)$ \\
\hline \multicolumn{3}{|l|}{ Physical fatigue } \\
\hline Severe fatigue & $453(32.0)$ & $5.2(1.1)$ \\
\hline No fatigue & $982(68.0)$ & $1.0(1.1)$ \\
\hline \multicolumn{3}{|l|}{ Mental fatigue } \\
\hline Severe fatigue & $372(26.0)$ & $2.3(0.5)$ \\
\hline No fatigue & $1063(74.0)$ & $0.2(0.3)$ \\
\hline Positive religious coping & & $17.8(4.5)$ \\
\hline Negative religious coping & & $9.3(3.2)$ \\
\hline
\end{tabular}

income decline (depression $\mathrm{OR}=1.63, p<0.001$; anxiety $\mathrm{OR}=1.49, p<0.001$ ), tracking regularly COVID-19 news (depression $\mathrm{OR}=1.79, p<0.01$; anxiety $\mathrm{OR}=1.97, p<$ 0.001), fear of contracting COVID-19 (depression OR = $2.24,<0.001$; anxiety $\mathrm{OR}=3.28, p<0.001$ ), and fear of dying from COVID-19 (depression OR $=6.46, p<0.001$; anxiety $\mathrm{OR}=11.03, p<0.001$ ) showed significant association with both anxiety and depression (HADS scores of 8 and above for both anxiety and depression).

Participants with a chronic illness had $1.89(p<0.001)$ higher odds of having anxiety symptoms. Meanwhile, respondents who were satisfied with their life during the COVID-19 pandemic were less likely to be depressed or anxious $(\mathrm{OR}=0.28,95 \% \mathrm{CI}: 0.21-0.37)$ and $(\mathrm{OR}=0.33$, 95\% CI: $0.25-0.43)$ for depression and anxiety, respectively).

The correlations between the studied scales and subscales were moderate to strong and generally significant. CFS-Physical and mental fatigue, HADS-A, and HADS$\mathrm{D}$ were positively correlated with negative religious coping and inversely correlated with positive religious coping (Table 3).

Logistic regression analyses were conducted to examine the associations of sociodemographic factors, religious coping, mental fatigue, and physical fatigue with depression and anxiety under COVID-19 epidemicrelated factors (Table 4). The results of single regression analysis confirm the significant association of most factors described by the chi-squared test with depression and anxiety (Table 2). Besides, it appears that depressive and anxious patients used more negative religious coping, while positive religious coping was only slightly associated with depression. The results showed also that mental fatigue and physical fatigue were associated significantly and positively with depression as well as with anxiety. The findings remained significant even after adjusted in the multiple logistic regression model. The latter indicated that physical fatigue was significantly associated with depression ( $\mathrm{aOR}=3.35$, 95\% CI: 2.51$4.50)$ and anxiety (aOR $=3.14,95 \% \mathrm{CI}: 2.37-4.18)$, and 
Table 2 Analysis of the association between demographic characteristics with depression and anxiety (based on HADS scores) among the study subjects using Chi-square test

\begin{tabular}{|c|c|c|c|c|c|c|c|c|c|c|}
\hline \multirow[t]{2}{*}{ Variable } & \multicolumn{2}{|c|}{ Depression } & \multirow[t]{2}{*}{$x^{2}$} & \multirow[t]{2}{*}{ OR } & \multirow[t]{2}{*}{$95 \% \mathrm{Cl}$} & \multicolumn{2}{|l|}{ Anxiety } & \multirow[t]{2}{*}{$x^{2}$} & \multirow[t]{2}{*}{ OR } & \multirow[t]{2}{*}{$95 \% \mathrm{Cl}$} \\
\hline & $\begin{array}{l}\text { Positive } \\
\text { (n) }\end{array}$ & $\begin{array}{l}\text { Negative } \\
\text { (n) }\end{array}$ & & & & $\begin{array}{l}\text { Positive } \\
\text { (n) }\end{array}$ & $\begin{array}{l}\text { Negative } \\
\text { (n) }\end{array}$ & & & \\
\hline \multicolumn{11}{|l|}{ Age stages (years) } \\
\hline$\leq 45$ & 684 & 550 & $14.29 * * *$ & $1.81^{* * *}$ & $1.31-2.50$ & 555 & 679 & $9.89^{* * *}$ & $1.67^{* *}$ & $1.20-2.32$ \\
\hline$>45$ & 82 & 119 & & & & 66 & 135 & & & \\
\hline \multicolumn{11}{|l|}{ Gender } \\
\hline Female & 376 & 248 & $20.49 * * *$ & $1.63^{* * *}$ & $1.31-2.04$ & 341 & 283 & $57.35^{* * *}$ & $2.28^{* * *}$ & $1.81-2.85$ \\
\hline Male & 390 & 421 & & & & 280 & 531 & & & \\
\hline \multicolumn{11}{|l|}{ Marital status } \\
\hline Married & 307 & 301 & 3.333 & 0.81 & $0.65-1.01$ & 259 & 349 & 0.15 & 0.95 & $0.76-1.19$ \\
\hline Not married & 459 & 368 & & & & 362 & 465 & & & \\
\hline \multicolumn{11}{|l|}{ Status as a parent } \\
\hline Having children & 226 & 243 & $7.24^{* *}$ & $0.73^{* *}$ & $0.58-0.91$ & 195 & 274 & 0.72 & 0.90 & $0.71-1.13$ \\
\hline No children & 540 & 426 & & & & 426 & 540 & & & \\
\hline \multicolumn{11}{|l|}{ Education } \\
\hline Higher education & 711 & 621 & 7.46 & 1.00 & $0.66-1.53$ & 574 & 758 & 0.16 & 0.90 & $0.59-1.38$ \\
\hline $\begin{array}{l}\text { Primary or secondary } \\
\text { education }\end{array}$ & 55 & 48 & & & & 47 & 56 & & & \\
\hline \multicolumn{11}{|l|}{ Living arrangements } \\
\hline Alone & 67 & 55 & 0.07 & 1.07 & $0.72-1.58$ & 48 & 74 & 0.67 & 0.83 & $0.56-1.25$ \\
\hline Not alone & 699 & 614 & & & & 573 & 740 & & & \\
\hline \multicolumn{11}{|c|}{ Household income decline } \\
\hline Yes & 250 & 153 & $16.39 * * *$ & $1.63^{* * *}$ & $1.28-2.08$ & 203 & 200 & $11.10^{* * *}$ & $1.49 * * *$ & $1.17-1.88$ \\
\hline No & 516 & 516 & & & & 418 & 614 & & & \\
\hline \multicolumn{11}{|c|}{ Life satisfaction during the COVID-19 pandemic } \\
\hline Satisfied & 529 & 595 & $81.96^{* * *}$ & $0.28^{* * *}$ & $0.21-0.37$ & 420 & 704 & $72.66^{* * *}$ & $0.33^{* * *}$ & $0.25-0.43$ \\
\hline Not satisfied & 237 & 74 & & & & 201 & 110 & & & \\
\hline \multicolumn{11}{|l|}{ Looked up regular news } \\
\hline Regularly & 712 & 589 & $9.59^{* *}$ & $1.79^{* *}$ & $1.23-2.63$ & 582 & 719 & $11.46^{* * *}$ & $1.97^{* * *}$ & $1.31-3.03$ \\
\hline Seldom & 54 & 80 & & & & 39 & 95 & & & \\
\hline \multicolumn{11}{|c|}{ Compliance with protective measures } \\
\hline High & 505 & 474 & 3.78 & 0.79 & $0.63-1.00$ & 429 & 550 & 0.31 & 1.07 & $0.85-1.35$ \\
\hline Low & 261 & 195 & & & & 192 & 264 & & & \\
\hline \multicolumn{11}{|c|}{ Compliance with quarantine measures } \\
\hline High & 651 & 562 & 0.19 & 1.07 & $0.80-1.44$ & 526 & 687 & 0.01 & 1.02 & $0.75-1.38$ \\
\hline Low & 115 & 107 & & & & 95 & 127 & & & \\
\hline \multicolumn{11}{|l|}{ Chronic illness } \\
\hline Yes & 76 & 47 & 3.46 & 1.45 & $0.98-2.17$ & 71 & 52 & $10.81^{* *}$ & $1.89^{* * *}$ & $1.28-2.81$ \\
\hline No & 690 & 622 & & & & 550 & 762 & & & \\
\hline \multicolumn{11}{|l|}{ Fear of COVID-19 } \\
\hline High & 303 & 151 & $46.85^{* * *}$ & $2.24^{* * *}$ & $1.75-2.85$ & 286 & 168 & $104.04^{* * *}$ & $3.28^{* * *}$ & $2.56-4.16$ \\
\hline Low & 463 & 518 & & & & 335 & 646 & & & \\
\hline Fear of dying from COVI & & & & & & & & & & \\
\hline High & 87 & 13 & $47.38^{* * *}$ & $6.46^{* * *}$ & $3.57-12.5$ & 88 & 12 & $85.64^{* * *}$ & $11.03^{* * *}$ & $5.88-25.0$ \\
\hline
\end{tabular}


Table 2 Analysis of the association between demographic characteristics with depression and anxiety (based on HADS scores) among the study subjects using Chi-square test (Continued)

\begin{tabular}{|c|c|c|c|c|c|c|c|c|c|c|}
\hline \multirow[t]{2}{*}{ Variable } & \multicolumn{2}{|c|}{ Depression } & \multirow[t]{2}{*}{$x^{2}$} & \multirow[t]{2}{*}{ OR } & \multirow[t]{2}{*}{$95 \% \mathrm{Cl}$} & \multicolumn{2}{|l|}{ Anxiety } & \multirow[t]{2}{*}{$x^{2}$} & \multirow[t]{2}{*}{ OR } & \multirow[t]{2}{*}{$95 \% \mathrm{Cl}$} \\
\hline & $\begin{array}{l}\text { Positive } \\
\text { (n) }\end{array}$ & $\begin{array}{l}\text { Negative } \\
\text { (n) }\end{array}$ & & & & $\begin{array}{l}\text { Positive } \\
\text { (n) }\end{array}$ & $\begin{array}{l}\text { Negative } \\
\text { (n) }\end{array}$ & & & \\
\hline Low & 679 & 656 & & & & 533 & 802 & & & \\
\hline \multicolumn{11}{|c|}{ Know someone died from COVID-19 } \\
\hline Yes & 15 & 19 & 0.85 & 0.68 & $0.32-1.43$ & 15 & 19 & 3.37 & 1.03 & $0.49-2.17$ \\
\hline No & 751 & 650 & & & & 606 & 795 & & & \\
\hline
\end{tabular}

X2 Chi-square test, OR odds ratio, $\mathrm{Cl}$ Confidence interval

${ }^{*} p<0.05,{ }^{* *} p<0.01,{ }^{* * *} p<0.001$

mental fatigue predicted significantly depression $(\mathrm{aOR}=$ 4.05, 95\% CI: 2.91-5.71) and anxiety ( $\mathrm{aOR}=3.80,95 \%$ CI: 2.78-5.20). Some sociodemographic variables remained significantly associated with depression and/or anxiety in multivariate logistic regression, including female gender, household income decline, tracking COVID-19 news, and having fear to contract this disease $(\mathrm{aOR}=1.36$ to 2.85$)$. The model had a Nagelkerke's $\mathrm{R}^{2}$ of 0.29 , and 0.36 for depression and anxiety, respectively. This suggests that about $29.0 \%$ of the depression variance and $36.0 \%$ of the anxiety variance could be explained by this model, though this should be interpreted with caution, since "pseudo" R2 values are derived differently in logistic regression compared with linear regression (Table 4).

\section{Discussion}

This study is a web-based survey aiming to examine the prevalence and associated variables of probable depressive and anxiety symptoms among 1435 respondents during the COVID-19 lockdown in Morocco. Therefore, the survey could have targeted only highly educated people having internet access. Unfortunately, this is one of the limitations of this study, because it is not representative of the general population.

The present findings demonstrated that nearly all respondents $(n=1301,91.0 \%)$ showed a need to be regularly updated with the latest information about COVID 19. This can be explained by the fact that our survey was carried out in the early stage of the COVID-19 outbreak in Morocco.

Importantly, the results of this survey revealed that most of the surveyed subjects expressed a high level of compliance with quarantine $(n=1213,85.0 \%)$, and protective measures (always washing hands, wearing a mask, and covering mouth when coughing and sneezing) $(n=$ $979,68.0 \%)$. These results can be partly explained by the fact that most respondents $(n=1332,93.0 \%)$ were highly educated, and might be attributed to the efficiency of authorities' awareness campaigns in the initial stage of the pandemic. Like few success stories [38], Morocco has adopted early quarantine measures, community mobilization, as well as large-scale testing of the population, which enabled the country to avoid a massive

Table 3 Correlations between Chalder Fatigue scale (CFS), Hospital Anxiety and Depression Scale (HADS), and Brief Religious Coping Scale (Brief RCOPE)

\begin{tabular}{|c|c|c|c|c|c|c|c|c|c|c|c|}
\hline & Mean & SD & $a$ & 2 & 3 & 4 & 5 & 6 & 7 & 8 & 9 \\
\hline 1- CFS - Physical fatigue & 2.34 & 2.27 & 0.82 & $0.58^{* * *}$ & $0.91^{* * *}$ & $0.56^{* * *}$ & $0.53^{* * *}$ & $0.59^{* * *}$ & -0.02 & $0.12^{* * *}$ & 0.05 \\
\hline 2- CFS - Mental fatigue & 0.75 & 1.04 & 0.61 & - & $0.51^{* * *}$ & $0.48^{* * *}$ & $0.48^{* * *}$ & $0.52^{* * *}$ & -0.03 & $0.14^{* * *}$ & $0.06^{*}$ \\
\hline 3- CFS - Total & 3.09 & 2.52 & 0.60 & & - & $0.49^{* * *}$ & $0.45^{* * *}$ & $0.51^{* * *}$ & -0.02 & $0.12^{* * *}$ & 0.05 \\
\hline 4- HADS - Depression & 7.19 & 4.10 & 0.76 & & & - & $0.69^{* * *}$ & $0.91^{* * *}$ & -0.04 & $0.16^{* * *}$ & $0.05^{*}$ \\
\hline 5- HADS - Anxiety & 6.38 & 4.62 & 0.88 & & & & - & $0.93^{* * *}$ & $0.09^{* * *}$ & $0.23^{* * *}$ & $0.19^{* * *}$ \\
\hline 6- HADS - Total & 13.58 & 8.01 & 0.89 & & & & & - & 0.03 & $0.21^{* * *}$ & $0.14^{* * *}$ \\
\hline 7- P RCOPE & 17.87 & 4.53 & 0.85 & & & & & & - & $0.19^{* * *}$ & $0.85^{* * *}$ \\
\hline 8- N RCOPE & 9.32 & 3.23 & 0.80 & & & & & & & - & $0.68^{* * *}$ \\
\hline 9- Brief RCOPE- Total & 27.19 & 6.04 & 0.81 & & & & & & & & - \\
\hline
\end{tabular}

SD Standard deviation, a Cronbach's a, CFS Physical fatigue Chalder Fatigue Scale - Physical fatigue subscale, CFS Mental fatigue Chalder Fatigue Scale - Mental fatigue subscale, CFS - Total Chalder Fatigue Scale - Total score, HADS - Depression Hospital Anxiety and Depression Scale - Depression subscale, HADS - Anxiety Hospital Anxiety and Depression Scale - Anxiety subscale, HADS - Total Hospital Anxiety and Depression Scale - Total score, P RCOPE positive religious coping subscale, N RCOPE negative religious coping subscale, Brief RCOPE- Total Brief Religious Coping Scale - Total score ${ }^{*} p<0.05,{ }^{* * *} p<0.001$ 
Table 4 Univariate and multivariate regression analysis of the association between religious coping, physical fatigue, mental fatigue, and sociodemographics with depression and anxiety

\begin{tabular}{|c|c|c|c|c|}
\hline \multirow[t]{2}{*}{ Variables } & \multicolumn{2}{|l|}{ Depression } & \multicolumn{2}{|l|}{ Anxiety } \\
\hline & OR $(95 \% \mathrm{Cl})$ & aOR $(95 \% \mathrm{Cl})$ & OR $(95 \% \mathrm{Cl})$ & aOR $(95 \% \mathrm{Cl})$ \\
\hline Age (Years) & $0.97(0.96-0.98)^{* * *}$ & $0.99(0.97-1.02)$ & $0.98(0.97-0.99)^{* * *}$ & $1.00(0.98-1.02)$ \\
\hline \multicolumn{5}{|l|}{ Age stages (Years) } \\
\hline$\leq 45$ & 1 & 1 & 1 & 1 \\
\hline$>45$ & $0.55(0.41-0.75)^{* * *}$ & $0.87(0.50-1.51)$ & $0.60(0.43-0.82)^{* * *}$ & $0.70(0.39-1.26)$ \\
\hline \multicolumn{5}{|l|}{ Gender } \\
\hline Male & 1 & 1 & 1 & 1 \\
\hline Female & $1.63(1.31-2.04)^{* * *}$ & $1.36(1.06-1.75)^{*}$ & $2.28(1.81-2.85)^{* * *}$ & $2.04(1.56-2.70)^{* * *}$ \\
\hline \multicolumn{5}{|l|}{ Status as a parent } \\
\hline Having children & 1 & 1 & 1 & 1 \\
\hline No children & $1.36(1.09-1.70)^{* *}$ & $0.92(0.67-1.27)$ & $1.11(0.89-1.39)$ & $0.69(0.49-0.98)^{*}$ \\
\hline \multicolumn{5}{|l|}{ Education } \\
\hline Higher education & 1 & 1 & 1 & 1 \\
\hline Primary or secondary education & $1.00(0.67-1.50)$ & $1.18(0.74-1.87)$ & $1.11(0.74-1.66)$ & $1.17(0.71-1.90)$ \\
\hline \multicolumn{5}{|l|}{ Employment status } \\
\hline Employed & 1 & 1 & 1 & 1 \\
\hline Unemployed & $1.05(0.71-1.56)$ & $1.20(0.76-1.92)$ & $1.29(0.87-1.90)$ & $1.47(0.90-2.38)$ \\
\hline \multicolumn{5}{|l|}{ Household income decline } \\
\hline No & 1 & 1 & 1 & 1 \\
\hline Yes & $1.63(1.28-2.08)^{* * *}$ & $1.40(1.07-1.85)^{*}$ & $1.49(1.17-1.88)^{* * *}$ & $1.33(1.01-1.75)$ \\
\hline \multicolumn{5}{|l|}{ Looked up regular news } \\
\hline Seldom & 1 & 1 & 1 & 1 \\
\hline Regularly & $1.79(1.23-2.63)^{* * *}$ & $1.66(1.09-2.56)^{*}$ & $1.97(1.31-3.03)^{* * *}$ & $1.58(1.01-2.56)$ \\
\hline \multicolumn{5}{|l|}{ Fear of COVID-19 } \\
\hline Low & 1 & 1 & 1 & 1 \\
\hline High & $2.24(1.75-2.85)^{* * *}$ & $1.75(1.35-2.32)^{* * *}$ & $3.28(2.56-4.16)^{* * *}$ & $2.85(2.17-3.70)^{* * *}$ \\
\hline \multicolumn{5}{|l|}{ CFS-Physical fatigue } \\
\hline No fatigue & 1 & 1 & 1 & 1 \\
\hline Severe fatigue & $5.90(4.55-7.72)^{* * *}$ & $3.35(2.51-4.50)^{* * *}$ & $5.44(4.28-6.96)^{* * *}$ & $3.14(2.37-4.18)^{* * *}$ \\
\hline \multicolumn{5}{|l|}{ CFS-Mental fatigue } \\
\hline No fatigue & 1 & 1 & 1 & 1 \\
\hline Severe fatigue & $7.69(5.69-10.61)^{* * *}$ & $4.05(2.91-5.71)^{* * *}$ & $6.82(5.22-8.98)^{* * *}$ & $3.80(2.78-5.20)^{* * *}$ \\
\hline P RCOPE & $0.99(0.96-1.01)$ & $0.97(0.95-1.00)$ & $1.03(1.01-1.06)^{* *}$ & $1.01(0.98-1.04)$ \\
\hline N RCOPE & $1.08(1.05-1.12)^{* * *}$ & $1.05(1.01-1.09)^{*}$ & $1.14(1.10-1.18)^{* * *}$ & $1.11(1.07-1.16)^{* * *}$ \\
\hline Nagelkerke $R^{2}$ for the model & 0.29 & & & 0.36 \\
\hline
\end{tabular}

OR odds ratio, $a O R$ adjusted odds ratio, $C$ confidence interval, CFS- Physical fatigue Chalder Fatigue Scale - Physical fatigue subscale, CFS - Mental fatigue Chalder Fatigue Scale - Mental fatigue subscale, $P$ RCOPE Positive religious coping, $N$ RCOPE Negative religious coping

${ }^{*} p<0.05,{ }^{* *} p<0.01,{ }^{* * *} p<0.001$

outbreak. Interestingly, the compliance with quarantine and protective measures was associated neither with depression nor with anxiety.

For concerns about COVID-19, 32.0\% $(n=454)$ of the subject's study expressed a high level of fear to contract COVID-19, and only 7.0\% $(n=100)$ expressed a high level of fear to die from this disease. The fact that $91.0 \%$
( $n=1312)$ of participants had no chronic disease might explain why they were less afraid to contract COVID-19 and to die if infected.

Concerning the psychological impact of COVID-19 and quarantine measured by HADS, results revealed that $53.0 \%(n=766)$ and $43.0 \%(n=621)$ of the participants were respectively found to be depressed and anxious 
(HADS scores of 8 and above for both anxiety and depression). The elevated rates of depression and anxiety found in this study could be caused by other factors which were not measured in this study, mainly sleep disturbance. The latter was ascertained to be associated with anxiety, depression, and suicidal behavior [39]. Indeed, the prevalence of depression (14.6 to 48.3\%) and anxiety symptoms (6.33 to $50.9 \%$ ), stress disorder (7 to $53.8 \%$ ), psychological distress (34.43 to $38 \%$ ), and stress (8.1 to $81.9 \%$ ) is higher during the COVID-19 outbreak than before in many countries [40]. In the United States, the depression prevalence was 3-fold higher during the COVID-19 outbreak than before [41], 32.7\% of adults from the Chinese general population experienced elevated anxiety or depressive symptoms [42]. Moreover, nearly half of the Libyan population suffered from depressive symptoms, and one-fifth presented severe anxiety symptoms $[43,44]$.

Univariate logistic regression showed that depression and anxiety were associated with younger age and female gender, while multivariate logistic regression indicated that only female gender remained significant. Our results showed that depression and anxiety were more likely to occur in younger people age 45 years or younger. These findings are corroborated by a previous study in Morocco, which revealed that people aged less than 35 years present more depressive and anxiety symptoms than those aged 35 years or older [45]. Moreover, previous studies undertaken on the Chinese population have demonstrated that younger participants are more likely inclined to undergo unemployment, income decline, high frequency of access to pandemic news through social media, and prone to develop anxiety and depressive symptoms during COVID-19 outbreak than those aged above 40 years [42, 46, 47]. Concerning the female gender, its association with depression and anxiety during COVID-19 pandemic was found in several epidemiological studies [45, 48-50]. In Morocco, the prevalence of depression and anxiety among women is high compared to men $[35,36]$. The differential risk of depression and anxiety may stem from biological sex differences, and COVID-19 related factors, such as lockdown, unemployment, and family violence [51, 52]. Previous studies have ascertained that violence against women leads to subsequent depression and anxiety [53, 54]. Accordingly, the rate of violence toward Moroccan women is estimated at around 54.4\% [55], and it is susceptive to rise significantly under pandemic and resultant shutdowns $[14,49,52,53,56]$. In this regard, it is reasonable to hypothesize that violence against Moroccan women may be one stressor among others that are associated with the higher prevalence of depression and anxiety recorded during the COVID-19 outbreak. Of Note, other stressors such as chronic health issues, exercise, financial problems, excess information from mass media, and infection fears were reported to be associated with depression, anxiety, distress and life satisfaction [14, 57-60].

The present study demonstrated that the likelihood of having depression and/or anxiety was higher in participants reporting mental and/or physical fatigue. Indeed, fatigue and depression share specific symptoms such as sleep disturbances, poor concentration, and memory difficulties [43, 61]. This explains why patients with either fatigue or depression are reported to be two-fold prone to show an increased risk for the comorbid presentation of both traits, compared to the general population [62].

Fatigue, depression, and anxiety in the present study were negatively correlated with positive religious coping, and positively correlated with negative religious coping. These findings confirmed the widespread belief that religiosity provides a source of attitudes that can reframe negative events into less stressful frames [63]. Thereby, positive religious coping and the trust in God correlate with less stress and increased positive impact $[64,65]$, when negative religious coping is usually linked to undesirable physical and mental health indicators such as depression, anxiety, and fatigue [64-66]. The weak association found in this study between positive religious coping and depression, was reported in other studies which mentioned that in samples experiencing a specific challenge, the association between positive religious coping and depression is somewhat weaker or conflicting [67].

The results of this study should be interpreted in light of the following limitations. First, due to the limited resources available and the time-sensitivity of the COVID19 outbreak, the snowball sampling strategy was adopted as a safe and the only option available during the total lockdown. The sampling was somehow biased since the questionnaire was administered to highly educated people who are the most internet users. Hence, these findings cannot, however, be extrapolated to all Moroccan populations. Second, this study did not collect contact details and personal information from the respondents mainly due to the ethical requirements on anonymity and confidentiality. As a result, we could not conduct a prospective study on the same group of participants in the future. Third, our findings were based on self-report data. Self-reported levels of depression, anxiety, and fatigue might be biased and may not always be aligned with assessment by health professionals. Notwithstanding the above limitations, this study provides invaluable information, from respondents across Morocco, about the initial psychological impact, fatigue, and religious coping associated with the spread of the COVID-19 and the lockdown on the Moroccan population. 


\section{Conclusions}

Overall, this study is one among few studies that have assessed the effects of the COVID-19 pandemic on depression, anxiety, fatigue, and religious coping among the Moroccan general population. It showed that the likelihood of having depression and anxiety was higher in participants reporting mental or physical fatigue and who had experienced negative religious coping. However, the likelihood of having depression and anxiety was lower in participants with positive religious coping. This highlights the importance of the development of psychological interventions to minimize psychological impact, anxiety, and depression, during the outbreak of COVID19. Further research about the psychological impact of COVID - 19 and religious coping in Morocco is recommended especially to be compared to our work that was carried out at the beginning of the pandemic.

\section{Abbreviations}

a: Cronbach's a; Brief RCOPE: Brief Religious Coping Scale; CFS: Chalder Fatigue Scale; CFS - Mental fatigue: Chalder Fatigue Scale - Mental fatigue subscale; CFS- Physical fatigue: Chalder Fatigue Scale - Physical fatigue subscale; Cl: Confidence interval; COVID-19: Coronavirus disease; HADS: Hospital Anxiety and Depression Scale - Total score; HADS Anxiety: Hospital Anxiety and Depression Scale - Anxiety subscale; HADS Depression: Hospital Anxiety and Depression Scale - Depression subscale; N RCOPE: Negative religious coping subscale; P RCOPE: Positive religious coping subscale; OR: Odds ratio

\section{Supplementary Information}

The online version contains supplementary material available at https://doi. org/10.1186/s12888-021-03271-6.

\section{Additional file 1}

\section{Acknowledgements}

We are grateful to all Moroccan citizens who participated in the study.

\section{Authors' contributions}

BZ has contributed to the conception and the design of the study, the acquisition, the analysis, and the interpretation of data, and has been involved in drafting the manuscript; NA has been involved in drafting, revising, and editing the manuscript; JE has been involved in the statistical analysis of data, revising, and editing the manuscript; AE has contributed to the conception and the design of the study, and the acquisition of data; SA has contributed to the acquisition of data; $\mathrm{MO}$ has contributed to the acquisition of data; HM has contributed to the acquisition of data; SB has contributed to the acquisition of data; SGM has contributed to the acquisition of data; $\mathrm{KH}$ has contributed to the conception and the design of the study; MER has contributed to the conception and the design of the study, and has given the final approval for the paper to be published. All authors have read and agreed to the published version of the manuscript. The author(s) read and approved the final manuscript.

\section{Funding}

There was no funding for this study.

\section{Availability of data and materials}

The datasets used and/or analysed during the current study are available from the corresponding author on reasonable request.

\section{Declarations}

\section{Ethics approval and consent to participate}

Ethical approval was obtained from the hospital-university ethics committee of Sidi Mohamed Ben Abdellah University ( $N^{\circ}$ 09/20). All respondents had provided electronic informed consent before starting the online investigation. All methods were carried out in accordance with relevant guidelines and regulations.

\section{Consent for publication}

Not applicable.

\section{Competing interests}

All the authors declare that they have no conflicts of interest.

\section{Author details}

'Laboratory of Epidemiology and Research in Health Sciences, Faculty of Medicine and Pharmacy, Sidi Mohamed Ben Abdellah University, Fez, Morocco. ${ }^{2}$ Teachers Training College (Ecole Normale Superieure), Department of Biology and Geology, Sidi Mohamed Ben Abdellah University, Fez, Morocco. ${ }^{3}$ Public Health Department, Faculty of Health Sciences, University of Balamand, Balamand, El-Koura, Lebanon. ${ }^{4}$ Laboratory of Pedagogical and Didactic Engineering of Sciences and Mathematics, Regional Center of Education and Training (CRMEF) of Fez, Fez, Morocco. ${ }^{5}$ Laboratory of Natural Substances, Pharmacology, Environment, Modeling, Health \& Quality of Life, Faculty of Sciences Dhar El Mahraz, Sidi Mohamed Ben Abdellah University, Fez, Morocco. ${ }^{6}$ Teachers Training College (Ecole Normale Superieure), Department of Human and Social Sciences - Education Sciences, Sidi Mohamed Ben Abdellah University, Fez, Morocco.

Received: 19 September 2020 Accepted: 7 May 2021

Published online: 22 May 2021

\section{References}

1. Johnson RM, Doshi P, Healy D. Covid-19: should doctors recommend treatments and vaccines when full data are not publicly available? BMJ. 2020;24:m3260

2. WHO Coronavirus (COVID-19) Dashboard. Available from: https://covid19. who.int. [cited 2021 Mar 14]

3. Coronavirus Update (Live): 122,489,407 Cases and 2,705,367 Deaths from COVID-19 Virus Pandemic - Worldometer. Available from: https://www. worldometers.info/coronavirus/. [cited 2021 Mar 19]

4. Morocco reports first coronavirus case: health ministry | Reuters. Available from: https://www.reuters.com/article/us-health-coronavirus-morocco/ morocco-reports-first-coronavirus-case-health-ministry-idUSKBN20P33T. [cited 2020 Sep 16]

5. Morocco Coronavirus: 500,948 Cases and 8,885 Deaths - Worldometer Available from: https://www.worldometers.info/coronavirus/country/ morocco/. [cited 2021 Apr 10]

6. Considerations for quarantine of contacts of COVID-19 cases. Available from: https://www.who.int/publications/i/item/considerations-for-quarantine-ofindividuals-in-the-context-of-containment-for-coronavirus-disease-(covid-19). [cited 2021 Mar 19].

7. Bao Y, Sun Y, Meng S, Shi J, Lu L. 2019-nCoV epidemic: address mental health care to empower society. Lancet Lond Engl. 2020;395(10224):e37-8. https://doi.org/10.1016/S0140-6736(20)30309-3.

8. Chang J, Yuan Y, Wang D. Mental health status and its influencing factors among college students during the epidemic of COVID-19. Nan Fang Yi Ke Da Xue Xue Bao. 2020;40(2):171-6. https://doi.org/10.12122/j.issn.1673-42 54.2020.02.06.

9. Wang C, Pan R, Wan X, Tan Y, Xu L, Ho CS, et al. Immediate Psychological Responses and Associated Factors during the Initial Stage of the 2019 Coronavirus Disease (COVID-19) Epidemic among the General Population in China. Int J Environ Res Public Health. 2020;17(5). Available from: https:// www.ncbi.nlm.nih.gov/pmc/articles/PMC7084952/ [cited 2020 Sep 16]

10. Xiang Y-T, Yang Y, Li W, Zhang L, Zhang Q, Cheung T, et al. Timely mental health care for the 2019 novel coronavirus outbreak is urgently needed. Lancet Psychiatry. 2020;7(3):228-9. https://doi.org/10.1016/S2215-0366(20)3 0046-8. 
11. Fardin MA. COVID-19 and Anxiety: A Review of Psychological Impacts of Infectious Disease Outbreaks. Arch Clin Infect Dis. 2020;15:e102779 Online ahead of Print (COVID-19).

12. Dong $M$, Zheng J. Letter to the editor: headline stress disorder caused by Netnews during the outbreak of COVID-19. Health Expect Int J Public Particip Health Care Health Policy. 2020;23(2):259-60.

13. Mukhtar S. Mental Health and psychosocial aspects of coronavirus outbreak in Pakistan: psychological intervention for public mental Health crisis. Asian J Psychiatr. 2020;51:102069. https://doi.org/10.1016/j.ajp.2020.102069.

14. Brooks SK, Webster RK, Smith LE, Woodland L, Wessely S, Greenberg N, et al. The psychological impact of quarantine and how to reduce it: rapid review of the evidence. Lancet. 2020;395(10227):912-20. https://doi.org/10.1016/ S0140-6736(20)30460-8.

15. Nitschke JP, Forbes P, Ali N, Cutler J, Apps MAJ, Lockwood P, et al. Resilience During Uncertainty. Greater Social Connectedness During COVID19 Lockdown is Associated with Reduced Distress and Fatigue. 2020; Available from: https://psyarxiv.com/9ehm7/ [cited 2020 Sep 16]

16. Chen YY, Koenig HG. Traumatic stress and religion: is there a relationship? A review of empirical findings. J Relig Health. 2006;45(3):371-81. https://doi. org/10.1007/s10943-006-9040-y.

17. Al-Hadethe A, Hunt N, Thomas S, Al-Qaysi A. Cross-cultural validation and psychometric properties of the Arabic Brief religious coping scale (A-BRCS). J Relig Health. 2016;55(1):16-25. https://doi.org/10.1007/s10943-014-9963-7.

18. Pargament Kl, Ensing DS, Falgout K, Olsen H, Reilly B, Haitsma KV, et al. God help me: (I): religious coping efforts as predictors of the outcomes to significant negative life events. Am J Community Psychol. 1990;18(6):793824. https://doi.org/10.1007/BF00938065.

19. Francis B, Gill JS, Yit Han N, Petrus CF, Azhar FL, Ahmad Sabki Z, et al. Religious coping, religiosity, depression and anxiety among medical students in a multi-religious setting. Int J Environ Res Public Health. 2019; 16(2):259. https://doi.org/10.3390/ijerph16020259.

20. Koenig HG, George LK, Siegler IC. The use of religion and other emotionregulating coping strategies among older adults. Gerontologist. 1988;28(3): 303-10. https://doi.org/10.1093/geront/28.3.303.

21. Pargament Kl, Tarakeshwar N, Ellison CG, Wulff KM. Religious coping among the religious: the relationships between religious coping and well-being in a National Sample of Presbyterian clergy, elders, and members. J Sci Study Relig. 2001;40(3):497-513. https://doi.org/10.1111/0021-8294.00073.

22. Koenig H, King D, Carson VB. Handbook of religion and Health. Oxford: Oxford University Press; 2012

23. Rosmarin $\mathrm{DH}$, Koenig HG. Handbook of spirituality, religion, and mental health. 2nd ed. London: Academic Press; 2020.

24. Lim C, Putnam RD. Religion, social networks, and life satisfaction. Am Sociol Rev. 2010;75(6):914-33. https://doi.org/10.1177/0003122410386686.

25. Aflakseir A, Coleman PG. Initial development of the Iranian religious coping scale. J Muslim Ment Health. 2011;6(1):44-61.

26. van der Velden PG, Contino C, Das M, van Loon P, Bosmans MWG. Anxiety and depression symptoms, and lack of emotional support among the general population before and during the COVID-19 pandemic. A prospective national study on prevalence and risk factors. J Affect Disord. 2020;277:540-8. https://doi.org/10.1016/j.jad.2020.08.026.

27. Zigmond AS, Snaith RP. The hospital anxiety and depression scale. Acta Psychiatr Scand. 1983;67(6):361-70. https://doi.org/10.1111/j.1600-0447.1983. tb09716.x.

28. Bjelland I, Dahl AA, Haug TT, Neckelmann D. The validity of the hospital anxiety and depression scale. An updated literature review. J Psychosom Res. 2002;52(2):69-77. https://doi.org/10.1016/S0022-3999(01)00296-3.

29. Smarr KL, Keefer AL. Measures of depression and depressive symptoms: Beck depression inventory-II (BDI-II), Center for Epidemiologic Studies Depression Scale (CES-D), geriatric depression scale (GDS), hospital anxiety and depression scale (HADS), and patient Health Questionnaire-9 (PHQ-9). Arthritis Care Res. 2011;63(Suppl 11):S454-66.

30. Terkawi AS, Tsang S, AlKahtani GJ, Al-Mousa SH, Musaed SA, AlZoraigi US, et al. Development and validation of Arabic version of the hospital anxiety and depression scale. Saudi J Anaesth. 2017;11(5):11. https://doi.org/10.41 03/sja.SJA_43_17.

31. Chalder T, Berelowitz G, Pawlikowska T, Watts L, Wessely S, Wright $D$, et al. Development of a fatigue scale. J Psychosom Res. 1993;37(2):147-53. https://doi.org/10.1016/0022-3999(93)90081-P.

32. Mcllvenny $S$. The translation into arabic and revalidation of a fatigue questionnaire. East Mediterr Health J. 1999;5(3):503-14.
33. Pargament Kl, Smith BW, Koenig HG, Perez L. Patterns of positive and negative religious coping with major life stressors. J Sci Study Relig. 1998; 37(4):710-24. https://doi.org/10.2307/1388152.

34. Pargament K, Feuille M, Burdzy D, The Brief RCOPE. Current psychometric status of a short measure of religious coping. Religions. 2011;2(1):51-76. https://doi.org/10.3390/rel2010051.

35. Moussaoui D. La santé mentale au Maroc : enquête nationale sur la prévalence des troubles mentaux et des toxicomanies. L'Encéphale. 2007;33: 125-6. https://doi.org/10.1016/S0013-7006(07)78685-2.

36. Kadri N, Agoub M, El Gnaoui S, Berrada S, Moussaoui D. Prevalence of anxiety disorders: a population-based epidemiological study in metropolitan area of Casablanca, Morocco. Ann General Psychiatry. 2007;6(1):6. https://doi. org/10.1186/1744-859X-6-6.

37. Nagelkerke NJD. A note on a general definition of the coefficient of determination. Biometrika. 1991;78(3):691-2. https://doi.org/10.1093/biomet/ 78.3.691.

38. Moris D, Schizas D. Lockdown during COVID-19: the Greek success. In Vivo. 2020;34(3 suppl):1695-9. https://doi.org/10.21873/invivo.11963.

39. Sher L. COVID-19, anxiety, sleep disturbances and suicide. Sleep Med. 2020; 70:124. https://doi.org/10.1016/j.sleep.2020.04.019.

40. Xiong J, Lipsitz O, Nasri F, Lui LMW, Gill H, Phan L, et al. Impact of COVID-19 pandemic on mental health in the general population: a systematic review. J Affect Disord. 2020;277:55-64. https://doi.org/10.1016/j.jad.2020.08.001.

41. Ettman CK, Abdalla SM, Cohen GH, Sampson L, Vivier PM, Galea S. Prevalence of depression symptoms in US adults before and during the COVID-19 pandemic. JAMA Netw Open. 2020;3(9):e2019686. https://doi. org/10.1001/jamanetworkopen.2020.19686.

42. Guo Y, Cheng C, Zeng Y, Li Y, Zhu M, Yang W, et al. Mental Health Disorders and Associated Risk Factors in Quarantined Adults During the COVID-19 Outbreak in China: Cross-Sectional Study. J Med Internet Res. 2020;22(8) Available from: https://www.ncbi.nlm.nih.gov/pmc/articles/ PMC7419152/ [cited 2021 Mar 16].

43. Elhadi M, Alsoufi A, Msherghi A, Alshareea E, Ashini A, Nagib T, et al. Psychological Health, Sleep Quality, Behavior, and Internet Use Among People During the COVID-19 Pandemic: A Cross-Sectional Study. Front Psychiatry. 2021;12 Available from: https://www.frontiersin.org/articles/10.33 89/fpsyt.2021.632496/full [cited 2021 Apr 8].

44. Msherghi A, Alsuyihili A, Alsoufi A, Ashini A, Alkshik Z, Alshareea E, et al. Mental Health Consequences of Lockdown During the COVID-19 Pandemic: A Cross-Sectional Study. Front Psychol. 2021;12 Available from: https://www. frontiersin.org/articles/10.3389/fpsyg.2021.605279/full [cited 2021 Apr 8].

45. Janati Idrissi A, Lamkaddem A, Benouajjit A, Ben El Bouaazzaoui M, El Houari $\mathrm{F}$, Alami M, et al. Sleep quality and mental health in the context of COVID19 pandemic and lockdown in Morocco. Sleep Med. 2020;74:248-53. https://doi.org/10.1016/j.sleep.2020.07.045

46. Huang Y, Zhao N. Generalized anxiety disorder, depressive symptoms and sleep quality during COVID-19 outbreak in China: a web-based crosssectional survey. Psychiatry Res. 2020;288:112954. https://doi.org/10.1016/j. psychres.2020.112954

47. Wang C, Song W, Hu X, Yan S, Zhang X, Wang X, et al. Depressive, anxiety, and insomnia symptoms between population in quarantine and general population during the COVID-19 pandemic: a case-controlled study. BMC Psychiatry. 2021;21(1):99. https://doi.org/10.1186/s12888-021-03108-2.

48. Özdin S, Bayrak Öş. Levels and predictors of anxiety, depression and health anxiety during COVID-19 pandemic in Turkish society: the importance of gender. Int J Soc Psychiatry. 2020;66(5):504-11. https://doi.org/10.1177/002 0764020927051

49. Raj A, Johns NE, Barker KM, Silverman JG. Time from COVID-19 shutdown, gender-based violence exposure, and mental health outcomes among a state representative sample of California residents. EClinicalMedicine. 2020; 26 Available from: https://www.ncbi.nlm.nih.gov/pmc/articles/PMC7444602/ [cited 2020 Sep 16].

50. Jiang W, Liu X, Zhang J, Feng Z. Mental health status of Chinese residents during the COVID-19 epidemic. BMC Psychiatry. 2020;20(1):580. https://doi. org/10.1186/s12888-020-02966-6.

51. Hou F, Bi F, Jiao R, Luo D, Song K. Gender differences of depression and anxiety among social media users during the COVID-19 outbreak in China:a cross-sectional study. BMC Public Health. 2020;20(1):1648. https://doi.org/1 0.1186/s12889-020-09738-7.

52. Thibaut F, van Wijngaarden-Cremers PJM. Women's Mental Health in the Time of Covid-19 Pandemic. Front Glob Womens Health. 2020;1 Available 
from: https:/www.frontiersin.org/articles/10.3389/fgwh.2020.588372/full [cited 2021 Mar 21].

53. Rees S, Silove D, Chey T, Ivancic L, Steel Z, Creamer M, et al. Lifetime prevalence of gender-based violence in women and the relationship with mental disorders and psychosocial function. JAMA. 2011;306(5):513-21. https://doi.org/10.1001/jama.2011.1098.

54. García-Moreno C, Pallitto C, Devries K, Stöckl H, Watts C, Abrahams N. Global and regional estimates of violence against women: prevalence and health effects of intimate partner violence and non-partner sexual violence. Geneva: World Health Organization; 2013. 50 p.

55. Kasraoui S. New Survey Shows High Rates of Violence Against Women in Morocco. Morocco: Morocco World News; 2019. Available from: https:// www.moroccoworldnews.com/2019/05/273120/survey-high-rates-violencewomen-morocco/ [cited 2021 Mar 18]

56. Malathesh BC, Das S, Chatterjee SS. COVID-19 and domestic violence against women. Asian J Psychiatr. 2020;53:102227.

57. Baxter AJ, Scott KM, Vos T, Whiteford HA. Global prevalence of anxiety disorders: a systematic review and meta-regression. Psychol Med. 2013;43(5): 897-910. https://doi.org/10.1017/S003329171200147X.

58. Galea S, Merchant RM, Lurie N. The mental Health consequences of COVID19 and physical distancing: the need for prevention and early intervention. JAMA Intern Med. 2020;180(6):817-8. https://doi.org/10.1001/jama internmed.2020.1562.

59. Zhang SX, Wang Y, Rauch A, Wei F. Unprecedented disruption of lives and work: Health, distress and life satisfaction of working adults in China one month into the COVID-19 outbreak. Psychiatry Res. 2020;288:112958. https:// doi.org/10.1016/j.psychres.2020.112958.

60. Ni MY, Yang L, Leung CMC, Li N, Yao XI, Wang Y, et al. Mental Health, risk factors, and social media use during the COVID-19 epidemic and cordon sanitaire among the community and Health professionals in Wuhan, China: Cross-Sectional Survey. JMIR Ment Health. 2020;7(5):e19009. https://doi.org/1 $0.2196 / 19009$

61. Larkin D, Martin CR. The interface between chronic fatigue syndrome and depression: a psychobiological and neurophysiological conundrum. Neurophysiol Clin Clin Neurophysiol. 2017;47(2):123-9. https://doi.org/10.101 6/j.neucli.2017.01.012.

62. Corfield EC, Martin NG, Nyholt DR. Co-occurrence and symptomatology of fatigue and depression. Compr Psychiatry. 2016;71:1-10. https://doi.org/10.1 016/j.comppsych.2016.08.004

63. Jenkins RA, Pargament KI. Religion and spirituality as resources for coping with cancer. J Psychosoc Oncol. 1995;13(1-2):51-74. https://doi.org/10.1300/ J077V13N01_04.

64. Abu-Raiya H, Ayten A, Tekke M, Agbaria Q. On the links between positive religious coping, satisfaction with life and depressive symptoms among a multinational sample of Muslims. Int J Psychol J Int Psychol. 2019;54(5):67886. https://doi.org/10.1002/ijop.12521.

65. Pirutinsky S, Cherniak AD, Rosmarin DH. COVID-19, mental Health, and religious coping among American orthodox Jews. J Relig Health. 2020;23:114.

66. Abu-Raiya $\mathrm{H}$, Pargament $\mathrm{K}$. Religious coping among diverse religions: commonalities and divergences; 2015.

67. Harrison MO, Koenig HG, Hays JC, Eme-Akwari AG, Pargament Kl. The epidemiology of religious coping: a review of recent literature. Int Rev Psychiatry. 2001;13(2):86-93. https://doi.org/10.1080/09540260124356.

\section{Publisher's Note}

Springer Nature remains neutral with regard to jurisdictional claims in published maps and institutional affiliations.

Ready to submit your research? Choose BMC and benefit from:

- fast, convenient online submission

- thorough peer review by experienced researchers in your field

- rapid publication on acceptance

- support for research data, including large and complex data types

- gold Open Access which fosters wider collaboration and increased citations

- maximum visibility for your research: over $100 \mathrm{M}$ website views per year

At BMC, research is always in progress.

Learn more biomedcentral.com/submissions 